\title{
Circulating Current and DC Current Ripple Control in MMC Under Unbalanced Grid Voltage
}

\author{
Yan Ma, Student Member, IEEE, Lingling Fan, Senior Member, IEEE
}

\begin{abstract}
This paper presents a control method for MMC under unbalanced grid voltage condition. The control method regulates the power, line current, and circulating current of a MMC. Under the unbalanced condition, the objective of control is to reduce the negative-sequence line current. Furthermore, the circulating current of a MMC consists not only double-line negative-sequence component, which appears under the balanced condition, but also positive- and zero-sequence double-line components. Thus the controller should be able to eliminate all those components of the circulating current. A proportional-resonant controller ( $P R$ controller) is applied to regulate the positive- and negative-sequence components of circulating current. In addition, the zero-sequence component of circulating current is controlled by a dc current controller. The proposed control method is verified in MATLAB/SimPowerSystem.
\end{abstract}

Index Terms-Modular Multilevel Converter, Circulating Current Suppression Control, DC Current Ripple Control, MATLAB/Simpowersystem, Proportion Resonance Controller

\section{INTRODUCTION}

$\mathbf{H}$ IGH voltage direct current (HVDC) has gained its popularity in recent years since HVDC has high capability for power transmission. HVDC is also a good choice to link different ac networks together [1]. Two types of converters are normally used to build HVDC system, voltage-source converter (VSC) and current-source converter [2].

Modular multilevel Converter (MMC), as a type of multilevel VSC, is first introduced in reference [3]. MMC requires much smaller size of grid side filter, since the output voltage of MMC has lower harmonics [4]. With the extensibility of several hundred of output voltage levels, MMC is ideal for high-voltage high-power applications such as HVDC transmission [5], high-voltage motor drives [6], and electric railways [7]. The topology of a three-phase MMC is shown in Fig. 1. Each phase of a MMC has two arms (upper and lower). For each arm, there are $N$ sub modules, and each sub module is a half bridge dc-dc converter. The output voltage level of a MMC is $N+1$.

Compare with traditional VSC, MMC has a unique problem, which is the circulating current flowing within the three phases of the converter [8]. Reference [9] built an analytical model of MMC and examined that under balanced grid condition, the circulating current consists of a double-line frequency negative-sequence component. Reference [10] presents a integrated control and switching strategy of a grid-connected MMC under balanced grid condition. Reference [1] proved

Y. Ma and L. Fan are with Dept. of Electrical Engineering, University of South Florida, Tampa FL 33620. Emails: linglingfan@usf.edu and yanma@mail.usf.edu. that during the unbalanced grid condition, circulating current consists of not only negative-sequence components, but also positive- and zero-sequence double-line components. A control strategy that suppresses the double-line frequency component of circulating current via $a c b$ to $d q$ transform has been developed in reference [8]. However, during the unbalanced grid condition, since there are positive- and zero-sequence components in circulating current, it is very complicated to add additional controller to control different sequence components separately. Reference [11] has developed circulating current suppression strategy with a PR controller for a passive load connected MMC. Reference [12] proposed a model predictive control (MPC) of MMC. MPC can control the output power, circulating current, and sub module capacitor voltage simultaneously without the sawtooth waveform and comparator which is required in PWM scheme. However, MPC scheme requires high amount calculation volume of the processor.

PR control strategies have been seen in the literature to deal with the unbalanced grid conditions. For example, [13] presented a Double Fed Induction Generator (DFIG) system connected to unbalanced grid condition. A PR controller-based control strategy has been developed to minimize rotor current harmonics and torque pulsations. Reference [14] presented a control scheme for a DFIG-based wind energy generation under unbalanced grid voltage conditions. To deal with the unbalanced grid condition, the system statements are separated into positive- and negative-sequence components and then be transformed to $d q$ frame separately. Reference [15] presented a control strategy for MMC that reduce the negativesequence component of line current to zero, and keep the positive-sequence current to generate to desired output power of converter. The output power has a double-line frequency component.

In this paper, MMC control strategy for unbalanced grid condition is presented and tested. The control strategy is trying to eliminate the double-line frequency component of the output real power of the MMC. Also the zero-sequence component elimination is also considered as a control objective. The dc side current ripples and resonances are suppressed by a dc current regulator. This paper is structured as follows. Section II explains the basic topology, operation, and plant models of MMC. Section III explains the proposed control system, which is separated into power control, current control, and circulating current and dc current control. A case study and simulation results are presented in Section IV followed by conclusions in Section V. 


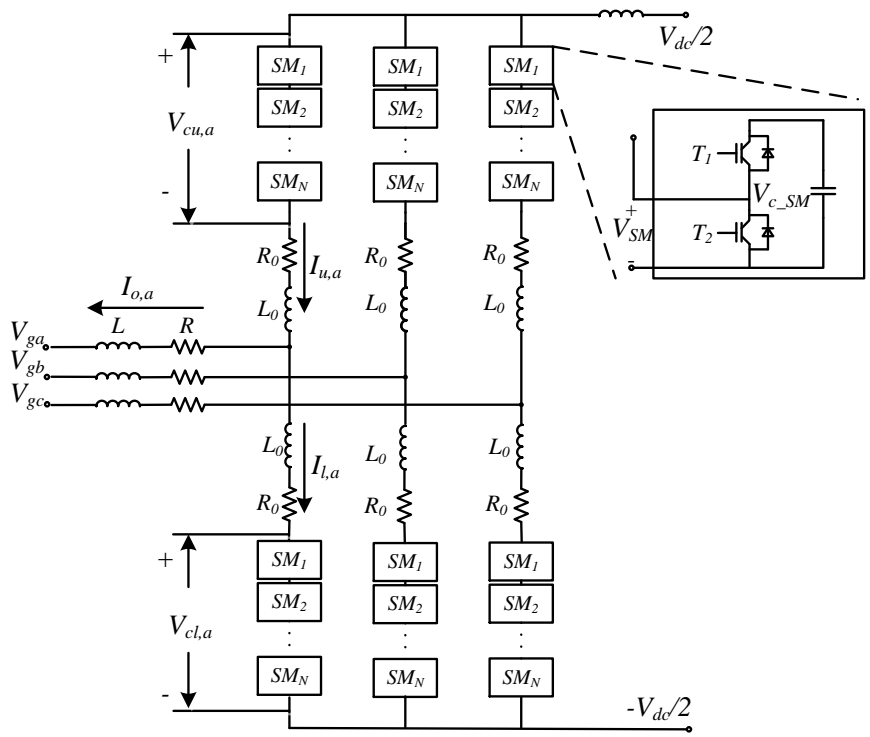

Fig. 1. Three-phase MMC topology.

\section{Plant Models For MMC CONTROL Under UNBALANCED CONDITION}

Fig. 1 shows the topology for a three-phase MMC consisting of six arms. On each arm, there are $N$ sub-modules and one arm inductor named as $L_{0}$. The IGBT switching loss of submodules is represented by a resister on arm named as $R_{0}$. Subscripts $u$ and $l$ denote upper and lower arms, respectively. The sub-module is half bridge dc-dc converters. The output of sub-module is either $U_{c}$ or 0 depending on the gate statement. When $N$ is big enough or the switching frequency is high enough, the voltage injection to each arm by sub-modules can be considered as continuous. For DC side voltage, with big DC-side capacitor, the dc-side voltage can be considered as a constant value. Thus, the single phase-equivalent circuit of a MMC can be expressed as Fig. 2.

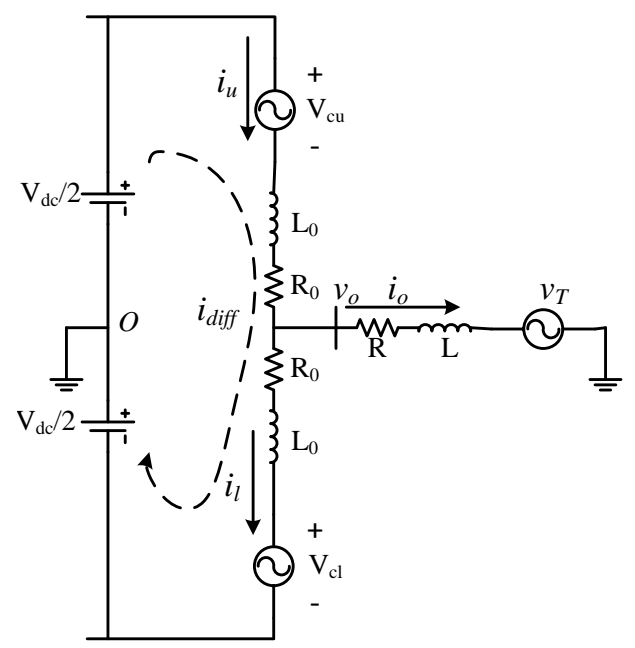

Fig. 2. Single phase equivalent circuit of MMC.

In Fig. 2, The upper and lower arm current are named as $i_{u}$ and $i_{l}$; the converter's output current and voltage are named as $i_{o}$ and $v_{o}$ respectively. The circulating current flowing within the converter is denoted as $i_{\text {diff }}$. Since the upper and lower arm are symmetric, ideally both lower and upper arm currents contain half of the converter output current. Therefore, with $\mathrm{KCL}$, we can get following equations:

$$
\left\{\begin{array} { l } 
{ i _ { u } = i _ { \mathrm { diff } } + \frac { i _ { o } } { 2 } } \\
{ i _ { l } = i _ { \mathrm { diff } } - \frac { i _ { o } } { 2 } }
\end{array} \Rightarrow \left\{\begin{array}{l}
i_{\mathrm{diff}}=\frac{i_{u}+i_{l}}{2} \\
i_{o}=i_{u}-i_{l}
\end{array}\right.\right.
$$

The voltage across the arm resistance and inductance can be expressed by the arm current. Therefore, with KVL, we can have the voltage relationship as follow:

$$
\left\{\begin{array}{l}
v_{u}+i_{u} R_{0}+L_{0} \frac{\mathrm{d} i_{u}}{\mathrm{~d} t}=\frac{V_{\mathrm{dc}}}{2}-v_{o} \\
v_{l}+i_{l} R_{0}+L_{0} \frac{\mathrm{d} i_{l}}{\mathrm{~d} t}=\frac{V_{\mathrm{dc}}}{2}+v_{o}
\end{array}\right.
$$

Considering that the output voltage $v_{o}$ can be written as $v_{g}+i_{o} R+L \frac{\mathrm{d} i_{o}}{\mathrm{~d} t}$ and (1), by substracting the two equations from (2) we have:

$$
\frac{v_{u}-v_{l}}{2}+\left(R+\frac{1}{2} R_{0}\right) i_{o}+\left(L+\frac{1}{2} L_{0}\right) \frac{\mathrm{d} i_{o}}{\mathrm{~d} t}+v_{g}=0
$$

It is obvious that the term $\frac{v_{u}-v_{l}}{2}$ in (3) drives the output current of the converter. Therefore we name this term as $e$, which is the inner EMF of the converter. We can have an equivalent circuit of MMC as Fig. 3, which is the plant model of inner current control loop of an MMC.

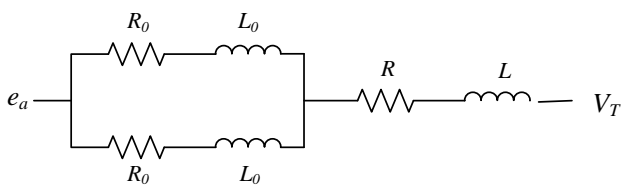

Fig. 3. An equivalent circuit of one phase of MMC.

Adding the two equations in (2) leads to the plant model of the circulating current control:

$$
i_{\mathrm{diff}} R_{0}+L_{0} \frac{\mathrm{d} i_{\mathrm{diff}}}{\mathrm{d} t}=\frac{V_{\mathrm{dc}}}{2}-\frac{v_{u}+v_{l}}{2} .
$$

The term $\frac{V_{\mathrm{dc}}}{2}-\frac{v_{u}+v_{l}}{2}$ in (4) is the voltage which drives the circulating current. We name this voltage as $e_{\text {diff. }}$. Considering the definitions of $e$ and $e_{\text {diff, }}$ we can have

$$
\left\{\begin{array}{l}
v_{u}=\frac{V_{\mathrm{dc}}}{2}+e-e_{\mathrm{diff}} \\
v_{l}=\frac{V_{\mathrm{dc}}}{2}-e-e_{\mathrm{diff}}
\end{array}\right.
$$

\section{Control System Under Unbalanced Voltage}

\section{A. PR Controller}

PR control can achieve high bandwidth at certain resonant frequency. Through PR control, measurement signal can track the reference signal without steady-state error at the resonance frequency. The ideal transfer function of a PR controller is shown in (6).

$$
G_{P R}(s)=K_{P}+\frac{K_{r} s}{s^{2}+\omega_{0}^{2}}
$$




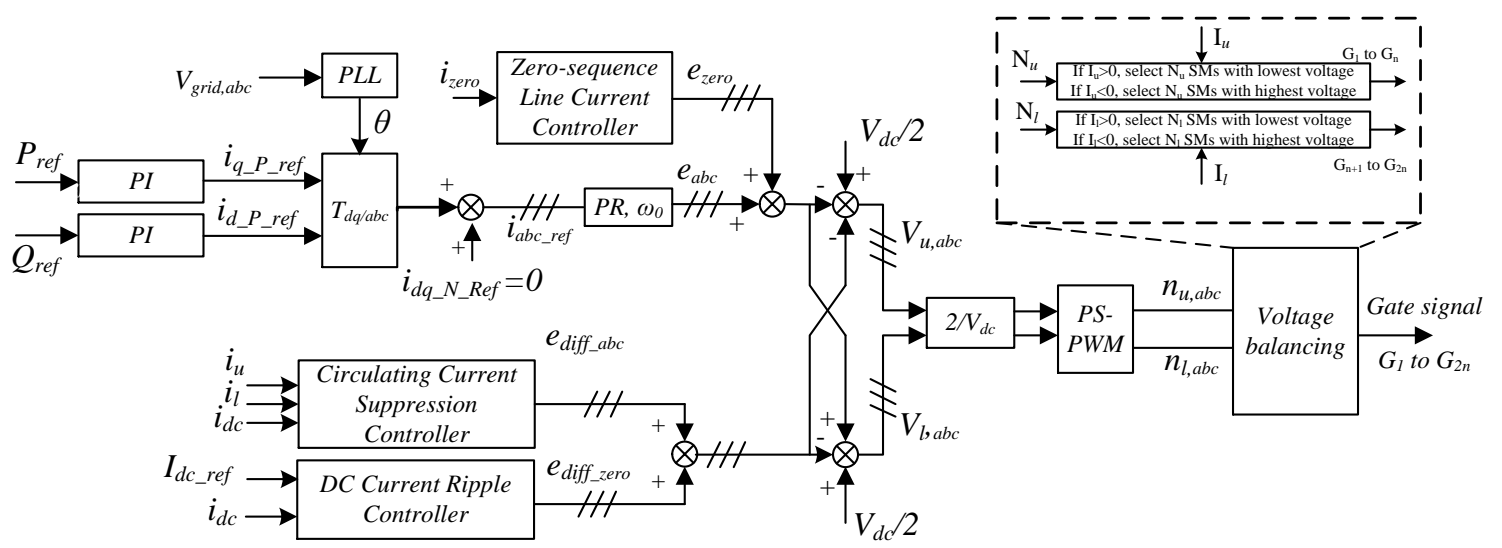

Fig. 4. Integrated MMC Control and Switching Under Unbalanced Grid Voltage.

The quasi-PR controller has a better noise rejection and has been applied for circulating current mitigation [16]. The transfer function of a quasi-PR controller is shown in (7).

$$
G_{Q P R}(s)=K_{P}+\frac{2 \omega_{c} K_{r} s}{s^{2}+2 \omega_{c} s+\omega_{0}^{2}}
$$

\section{B. Outer Loop Power Control}

When the grid side voltage is under unbalanced condition, the line current and power flow are separated in positive, negative- and zero-sequence components, which is shown in equation (8). With a zero-sequence current controller, the zero-sequence current can be reduced to zero. Therefore the objective of the unbalance controller is the negative component of line current.

$$
\left\{\begin{array}{l}
\vec{V}=\vec{V}^{+}+\vec{V}^{-}=V^{+} e^{j \omega t}+V^{-} e^{-j \omega t} \\
\vec{I}=\vec{I}^{+}+\vec{I}^{-}=I^{+} e^{j \omega t}+I^{-} e^{-j \omega t}
\end{array}\right.
$$

Where $\vec{V}$ and $\vec{I}$ are the space vectors of the voltage across the line and the line currents respectively. The superscription + and - denote the positive- and negative-component. With the equation of the complex power, $\vec{S}=3 / 2 \vec{V} \vec{I}^{*}$. Substituting (8) into the equation, we have:

$$
2 / 3 S=V^{+} I^{+*}+V^{-} I^{-*}+V^{+} I^{-*} e^{2 j \omega t}+V^{-} I^{+*} e^{-2 j \omega t}
$$

Considering the $d q$ frame, $V=V_{q}+j V_{d}$ and $I=I_{q}+$ $j I_{d}$. We have the following expression of three-phase complex power under unbalanced condition.

$$
\begin{aligned}
2 / 3 S & =\underbrace{V_{q}^{+} I_{q}^{+}+V_{d}^{+} I_{d}^{+}+V_{q}^{-} I_{q}^{-}+V_{d}^{-} I_{d}^{-}}_{P_{0}} \\
& +\underbrace{V_{d}^{+} I_{q}^{+}+V_{d}^{-} I_{q}^{-}-V_{q}^{+} I_{d}^{+}-V_{q}^{-} I_{d}^{-}}_{Q_{0}} \\
& +\left(V_{q}^{+} I_{q}^{-}+V_{d}^{+} I_{d}^{-}+V_{d}^{+} I_{q}^{-}-V_{q}^{+} I_{d}^{-}\right) e^{j 2 \omega t} \\
& +\left(V_{q}^{-} I_{q}^{+}+V_{d}^{-} I_{d}^{+}-V_{d}^{-} I_{q}^{+}-V_{q}^{-} I_{d}^{+}\right) e^{-j 2 \omega t}
\end{aligned}
$$

It is clear that during the unbalanced grid condition, the power flow through the line has a double-line frequency component. With Euler's formula, taking the real part of the complex power, the active power can be written as follow,

$2 / 3 P_{\text {line }}=P_{0}+P_{\sin (2 \omega t)} \sin (2 \omega t)+P_{\cos (2 \omega t)} \cos (2 \omega t)$

Where

$$
\left\{\begin{array}{l}
P_{\sin (2 \omega t)}=V_{d}^{+} I_{q}^{-}+V_{q}^{+} I_{d}^{-}+V_{d}^{-} I_{q}^{+}-V_{q}^{-} I_{d}^{+} \\
P_{\cos (2 \omega t)}=V_{d}^{-} I_{q}^{+}+V_{q}^{-} I_{q}^{+}+V_{d}^{+} I_{d}^{-}-V_{q}^{+} I_{q}^{-}
\end{array}\right.
$$

\section{Inner Loop Current Control}

Different control objectives have been set for MMC under unbalanced condition. Reference [15] tried to reduce the negative components of the line current to zero. With equation (10), when negative current is zero, the dc component of line power flow is controlled by positive current. The reference of positive current in $d q$ frame are generated by a standard out loop power control with PI controller. The reference of line current in $a b c$ frame is then generated with a $d q$-to$a b c$ transformer. Considering equation (12), when the negative component of line current is zero, with a non-zero negative grid voltage, $P_{\sin (2 \omega t)}$ and $P_{\cos (2 \omega t)}$ are not zero. Therefore, there is a double-line frequency component in line active power during the unbalanced condition.

\section{Grid-side Zero-Sequence Current Control}

The overall control structure is shown in Fig.4. The zero sequence current occurs during the unbalanced condition. A $Y-$ to $-\Delta$ transformer can stop the zero sequence current. However, when the fault happens on the transformer or between the transformer and MMC, zero-sequence current will not be stopped by transformer. Thus, it is necessary to control the zero-sequence current. The dynamics of zero-sequence current can be written as

$$
R i_{\text {zero }}(t)+L \frac{\mathrm{d} i_{\text {zero }}(t)}{\mathrm{d} t}=U_{\text {zero }}(t)-V_{g, \text { zero }}(t)
$$

Where $U_{\text {zero }}(t)$ is the zero-sequence component of converter output voltage and $V_{g, \text { zero }}(t)$ is the zero-sequence component of grid voltage. 
A feedback control loop with PI controller is applied to control the zero-sequence line current as shown in Fig.4. The reference of zero-sequence current is set as 0 . The output of the controller is the zero-sequence component of EMF of the MMC, which will reflect to the output voltage of MMC.

\section{E. Circulating Current Control and Dc Current Ripple Con- trol}

In an MMC, the difference between each phase's total sub-module capacitor voltage leads to the circulating current. Under balanced condition, it has been evaluated that circulating current consists of only negative-sequence double line frequency component, since the instantaneous power for each phase has a negative-sequence double line frequency component.

When the ac-side voltage has negative component, the instantaneous power of each phase consist not only negativesequence but also positive- and zero-sequence double-line frequency components. Therefore, to eliminate the circulating current under unbalanced condition, the controller in positive-, negative- and, zero-sequence are all needed.

$$
i_{\mathrm{diff}}=i_{\mathrm{dc}} / 3+i_{\mathrm{cir}}^{p}+i_{\text {cir }}^{n}
$$

Where $i_{\mathrm{diff}}$ is the inner unbalanced current, $I_{\mathrm{dc}}$ is the DCside current of MMC. Under the unbalanced grid condition, there will be a double-line frequency component in $I_{\mathrm{dc}}$ since there is a zero-sequence component in circulating current. The ac components of $i_{\text {diff }}$ is the circulating current, which should be eliminated. However, it is difficult to implement PI controller since the ac component consists of different sequence components. PR controller is suitable for the proposed control, since all the sequence components are at double-line frequency. In order to cancel the ac components of $i_{\text {diff. It's }}$ $\mathrm{dc}$ component is set as the reference of the PR controller. The output of PR controller is the positive- and negative-sequence components of the reference inner unbalanced voltage, which is noted as $e_{\text {diff,abc }}$ in Fig. 5.

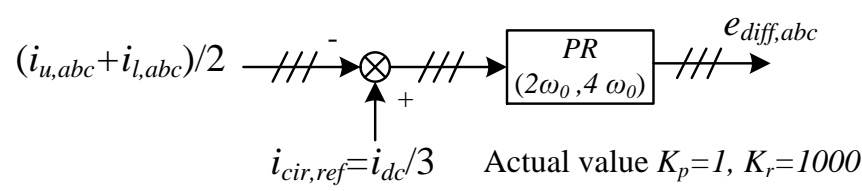

Fig. 5. Circulating current suppression controller.

For a three-phase system, the sum of positive- and negativesequence current are zero. However the sum of zero-sequence component is not zero. And $i_{\mathrm{dc}}$ is the sum of three-phase current. Therefore, if the three-phase current has zero-sequence component, then $i_{\mathrm{dc}}$ includes the zero-sequence component ripple. Normally, a $Y$-to- $\delta$ transformer can stop the zerosequence line current. However, when the fault happens between the transformer and MMC, or the system has no transformer, it is necessary to eliminate the zero-sequence line current. The controller to eliminate zero-sequence current is shown in Fig. 6. As shown in Fig. 4, the output of the zerosequence line current controller is added to the output of the inner loop current controller as a zero-sequence component.

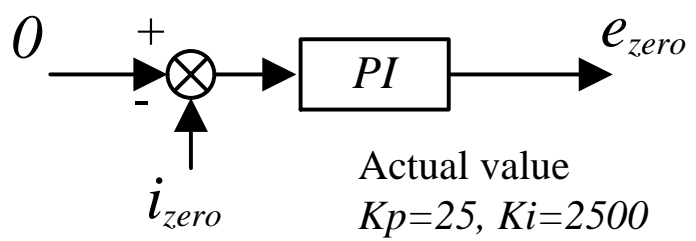

Fig. 6. Zero-sequence line current controller.

If we assume there is no power loss on MMC. Then the ac-side power of MMC should be equal to the dc-side power of MMC. So the dc component of the dc-side current can be easily set as $I_{\mathrm{dc}, \text { ref }}=P_{\text {out }} / V_{\mathrm{dc}}$. Where $P_{\text {out }}$ is the ac-side output power of MMC and $V_{\mathrm{dc}}$ is the dc supply voltage of MMC. A PR controller is used to control the zero-sequence of the inner difference current to $I_{\mathrm{dc}, \text { ref }}$. The output of PR controller is the zero-sequence component of the reference inner difference voltage. Beside the double-line frequency ripple, the dc current ripple controller can also cancel the resonance current caused by LC circuit resonant. A controller is added to reduce the dc current ripple as shown in Fig. 7. The output of the dc current ripple controller is added to the output of the circulating current suppression controller as shown in Fig. 4

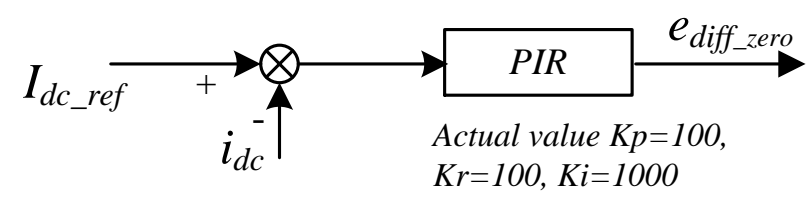

Fig. 7. DC-side current ripple controller.

\section{Simulation Results}

\section{A. Study System}

A simulation of the proposed system is conducted in MATLAB SimPowerSystem. The simulation environment and parameters are listed in table I. At $t=0.2 s$ the circulating current controller and the controller to eliminate the dc current ripple is activated. From $t=0.6 s$ to $t=0.8 s$, there is a $0.2 p u$ negative-sequence component voltage on the grid side. Regardless of the start-up process, the capacitor voltages of sub modules were charged at nominal value at beginning.

\section{B. Performance of the control system}

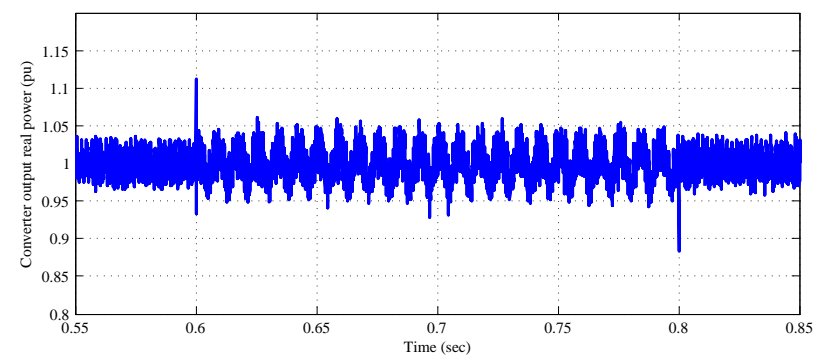

Fig. 8. Output real power of converter. 
TABLE I

CiRCUIT PARAMETERS AND OPERATING CONDITIONS OF THE SIMULATION

\begin{tabular}{l|l|c}
\hline Items & Values & Comments \\
\hline Active power $P$ & $10 \mathrm{MW}$ & $1.0 p . u$. \\
\hline Reactive power $Q$ & $1 \mathrm{MW}$ & $0.1 p . u$. \\
\hline Grid voltage & $20 \mathrm{kV}$ & $V_{\text {peak }} L-N$ \\
\hline Base power $S_{\text {base }}$ & $10 \mathrm{MW}$ & \\
\hline Base voltage $V_{\text {base }}$ & $20 \mathrm{kV}$ & \\
\hline Line inductance $L$ & $50 \mathrm{mH}$ & $0.4712 \mathrm{pu}$ \\
\hline Line resistance $R$ & $0.03 \Omega$ & $7.5 \times 10^{-4} p . u$. \\
\hline Arm inductance $L_{0}$ & $8 \mathrm{mH}$ & $0.0752 p . u$. \\
\hline Arm resistance $R_{0}$ & $0.1 \Omega$ & $0.0025 p . u$. \\
\hline DC bus voltage $V_{d c} / 2$ & $60 \mathrm{kV}$ & $V_{\mathrm{dc}}= \pm 30 \mathrm{kV}$ \\
\hline Number of SMs per arm $N$ & 4 & \\
\hline SM capacitance & $2500 \mu \mathrm{F}$ & \\
\hline SM capacitor voltage & $15000 \mathrm{~V}$ & \\
\hline Sampling time & $25 \mu \mathrm{s}$ & \\
\hline Carrier frequency of PWM & $2000 \mathrm{~Hz}$ & \\
\hline
\end{tabular}

Fig. 8 shows the output real power of the MMC. During the unbalanced voltage condition ( $t$ from 0.6 to 0.8 ), the output power has a double-line frequency component. When $I^{-}$is zero, with a non zero $V_{g}^{-}$, The double-line frequency component of line power is not zero.

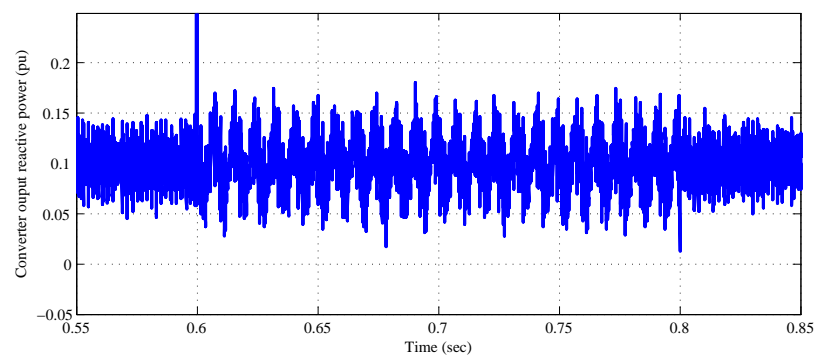

Fig. 9. Output reactive power of converter.

Fig.9 shows the output reactive power of the MMC. As the same with the output active power. During the unbalanced grid condition, there is a double-line frequency component appear on the converter output reactive power.

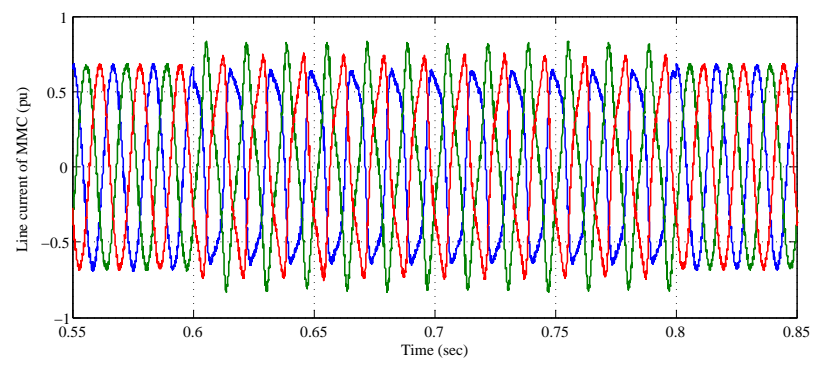

Fig. 10. Grid current of MMC.

Fig. 10 is the grid current of MMC during the unbalance condition. The ripple during the unbalanced condition is due to the changing of the power and reactive power. The out loop power controller tries to regulate the converter power to reference value. So the ripple of the power leads a ripple in current reference in $d q$ frame, and the ripple for reference current in $d q$ frame causes a ripple of line current in $a b c$ frame.

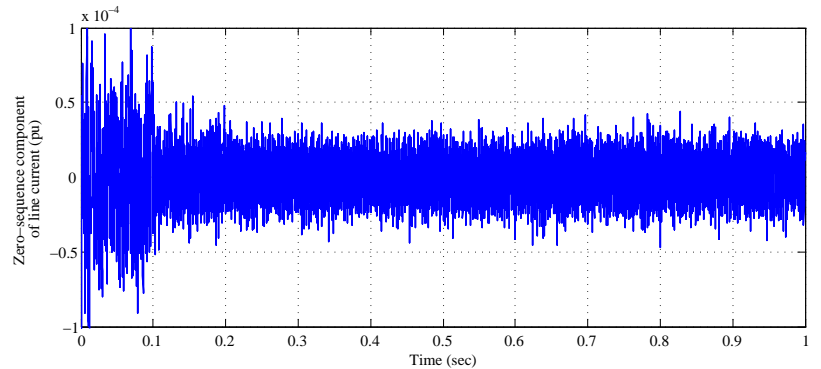

Fig. 11. Zero-sequence component of line current of MMC.

Fig. 11 is the zero-sequence component of line current. After applying the zero-sequence current controller at $t=0.1 \mathrm{~s}$, the magnitude of the zero-sequence current is reduced during both balanced and unbalanced condition.
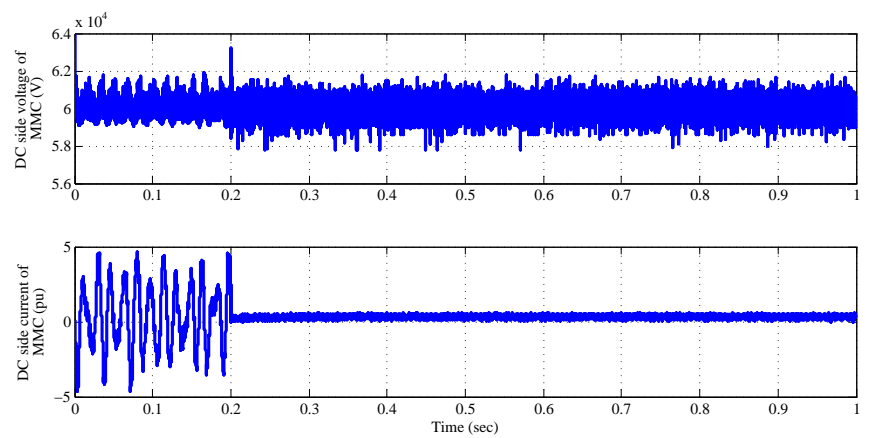

Fig. 12. DC side voltage and current

Fig. 12 shows the dc-side voltage and current characteristics of MMC. The dc current ripple controller is activated at $t=0.2 \mathrm{~s}$. It shows that before the activation of dc current ripple controller. There is a low frequency resonance on the dc current and voltage. The resonance is caused by the LC components in each arm of MMC. After applying the dc current controller, the resonance on dc-side is eliminated.

Fig. 13 is the phase a circulating current of MMC. At $t=$ $0.2 s$, the circulating current suppression controller is on. The magnitude of the circulating current is reduced from around $1500 A$ to around $100 A$. With smaller circulating current, the charging and discharging speed of sub module capacitors is smaller.

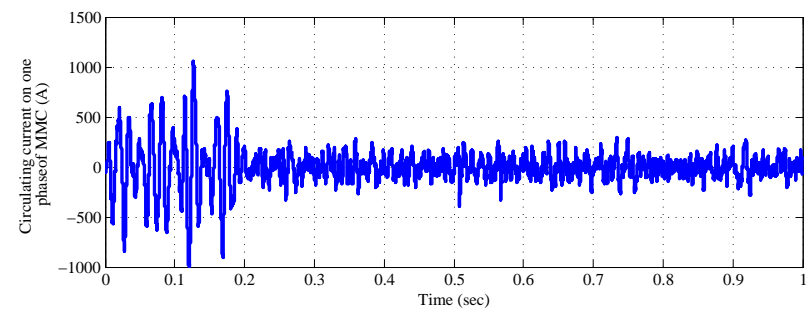

Fig. 13. Circulating current flow through phase a of MMC.

Fig. 14 shows that, after the circulating current controller is activated, the voltage ripple of the sub module capacitors voltages is much smaller. 


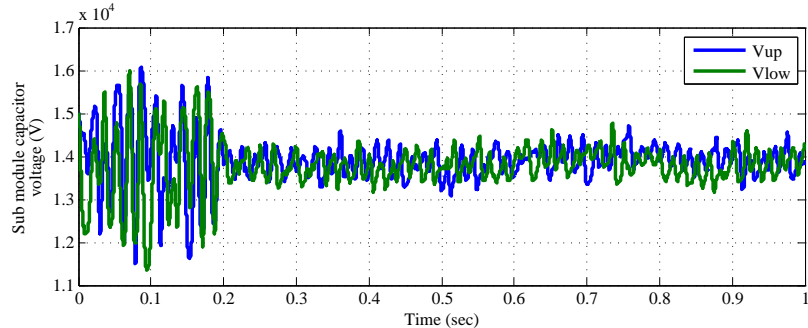

Fig. 14. Upper and lower arm sub module capacitor voltage of phase a of MMC.

\section{CONCLUSION}

This paper presents a control method for MMC under unbalanced grid voltage. When the negative-sequence component of the line current during unbalanced condition is controlled to zero, there is a double-line frequency component on the output power of MMC during unbalanced condition. With proper nonzero negative-sequence line current, the double-line frequency component of the output real power can be eliminated. The PR controller reduces both positive- and negative-sequence components of the circulating current during the unbalanced condition. In addition, a dc current controller is applied to reduce the zero-sequence of the circulating current and resonance current on the dc-side of MMC.

\section{REFERENCES}

[1] Q. Tu, Z. Xu, Y. Chang, and L. Guan, "Suppressing dc voltage ripples of mmc-hvdc under unbalanced grid conditions," Power Delivery, IEEE Transactions on, vol. 27, no. 3, pp. 1332-1338, July 2012.

[2] J.-W. Moon, C.-S. Kim, J.-W. Park, D.-W. Kang, and J.-M. Kim, "Circulating current control in mmc under the unbalanced voltage," Power Delivery, IEEE Transactions on, vol. 28, no. 3, pp. 1952-1959, July 2013.

[3] R. Marquardt, "Stromrichterschaltungen mit verteilten energiespeichern," German Patent DE, vol. 10, no. 103, p. 031, 2001.

[4] L. Franquelo, J. Rodriguez, J. Leon, S. Kouro, R. Portillo, and M. Prats, "The age of multilevel converters arrives," Industrial Electronics Magazine, IEEE, vol. 2, no. 2, pp. 28-39, June 2008.

[5] M. Saeedifard and R. Iravani, "Dynamic performance of a modular multilevel back-to-back hvdc system," Power Delivery, IEEE Transactions on, vol. 25, no. 4, pp. 2903-2912, Oct 2010.

[6] M. Hiller, D. Krug, R. Sommer, and S. Rohner, "A new highly modular medium voltage converter topology for industrial drive applications," in Power Electronics and Applications, 2009. EPE '09. 13th European Conference on, Sept 2009, pp. 1-10.

[7] M. Winkelnkemper, A. Korn, and P. Steimer, "A modular direct converter for transformerless rail interties," in Industrial Electronics (ISIE), 2010 IEEE International Symposium on, July 2010, pp. 562-567.

[8] Q. Tu, Z. Xu, and L. Xu, "Reduced switching-frequency modulation and circulating current suppression for modular multilevel converters," Power Delivery, IEEE Transactions on, vol. 26, no. 3, pp. 2009-2017, July 2011.

[9] L. Harnefors, A. Antonopoulos, S. Norrga, L. Angquist, and H.-P Nee, "Dynamic analysis of modular multilevel converters," Industrial Electronics, IEEE Transactions on, vol. 60, no. 7, pp. 2526-2537, July 2013.

[10] Y. Ma, L. Fan, and Z. Miao, "Integrated control and switching strategy for a grid-connected modular multilevel converter," in PES General Meeting, 2015 IEEE, accepted, July 2015, pp. 1-5.

[11] X. She, A. Huang, X. Ni, and R. Burgos, "Ac circulating currents suppression in modular multilevel converter," in IECON 2012 - 38th Annual Conference on IEEE Industrial Electronics Society, Oct 2012, pp. 191-196.

[12] Y. Ma, Z. Miao, V. R. Disfani, and L. Fan, "A one-step model predictive control for modular multilevel converters," in PES General Meeting Conference Exposition, 2014 IEEE, July 2014, pp. 1-5.
[13] L. Fan, R. Kavasseri, H. Yin, C. Zhu, and M. Hu, "Control of DFIG for rotor current harmonics elimination," in Power \& Energy Society General Meeting, 2009. PES'09. IEEE. IEEE, 2009, pp. 1-7.

[14] L. Fan, H. Yin, and Z. Miao, "A novel control scheme for DFIG-based wind energy systems under unbalanced grid conditions," Electric Power Systems Research, vol. 81, no. 2, pp. 254-262, 2011.

[15] M. Guan and Z. Xu, "Modeling and control of a modular multilevel converter-based hvdc system under unbalanced grid conditions," Power Electronics, IEEE Transactions on, vol. 27, no. 12, pp. 4858-4867, Dec 2012.

[16] D. Zmood, D. Holmes, and G. Bode, "Frequency-domain analysis of three-phase linear current regulators," Industry Applications, IEEE Transactions on, vol. 37, no. 2, pp. 601-610, Mar 2001. 